\title{
FINDING A MYCORRHIZAL FUNGUS FOR REINTRODUCTIONS OF THE THREATENED TERRESTRIAL ORCHID DIURIS FRAGRANTISSIMA
}

\author{
Zoe Smith ${ }^{1,3}$, Elizabeth A. James $^{2} \&$ Cassandra B. McLean ${ }^{1}$ \\ 'Burnley Campus, The University of Melbourne, 500 Yarra Boulevard, \\ Richmond \\ Victoria 3121, Australia \\ ${ }^{2}$ The Royal Botanic Gardens Melbourne, Australia \\ ${ }^{3}$ Author for correspondence: z.smith@pgrad.unimelb.edu.au
}

\begin{abstract}
Australian terrestrial orchids rely on associations with suitable mycorrhizal fungi for in situ seed germination and establishment, an important prerequisite for self sustaining populations. Finding an appropriate mycorrhizal fungus is therefore imperative to successful reintroductions. Reintroductions have been planned to conserve the terrestrial orchid Diuris fragrantissima, which is Critically Endangered in Victoria, Australia, having been reduced to less than 25 plants at a single site.

This study investigated the presence of a suitable mycorrhizal partner for Diuris fragrantissima in situ, ex situ and from closely related species, for use in reintroductions. Six hundred seed baits were placed at
\end{abstract}

three original sites of $D$. fragrantissima but did not recover a single germinant. Twenty-two fungi isolated from D. punctata, D. dendrobioides and D. chryseopsis, and ten fungi isolated from $D$. fragrantissima in ex situ collection were used in germination trials with seed of $D$. fragrantissima. Three isolates initiated germination, including fungi isolated from 'asymbiotic' ex situ D. fragrantissima. Germination rates were always below $30 \%$. Fungal isolates were identified by direct sequencing of the nuclear internal transcribed spacer and large subunit regions of DNA. All isolates were closely related to Tulasnella calospora.

Evolutionary relationships between fungi and their orchid hosts across Victoria are discussed.

Zoë Smith recently obtained her Ph.D. in resource management at the University of Melbourne, Australia. Her research focussed on the taxonomic status, genetic diversity, fungal ecology and systematic relationships, and reintroduction of Diuris fragrantissima. During her studies she was employed as an orchid researcher at the Royal Botanic Gardens Melbourne, and also held a short internship at the Royal Botanic Gardens, Kew, UK, where she conducted research on species extinction modelling. Zoë is currently employed as an environmental consultant and is looking for a post doctoral position. 